\title{
Study on the E-government Call Center System Based on SOA
}

\author{
Feng Bao \& Fengzhi Zhao \\ Northeast Petroleum University, Daqing 163318, China \\ E-mail: qhdcomputer@163.com
}

Received: June 15, 2011

Accepted: June 27, 2011

doi:10.5539/cis.v4n4p120

\begin{abstract}
An E-government service call center system based on SOA (Service-oriented Architecture) is designed, and the application of SOA in E-government, the overall design idea, the design plan, and the implementation of concrete functions are introduced in this article. With good flexibility and expandability, this system has good practical value and promotional value.
\end{abstract}

Keywords: Service-oriented Architecture (SOA), E-government, Call center system, Network design

With the quick development of the information technology, people's traditional life mode and work mode have been changed thoroughly. In recent years, because of the quickly development of the telecommunication business, many relative industries, and the information technology, many industries requires the call center urgently, especially for the government, the industry, the commerce, the taxation, the newspapering, the weather, and middle enterprises, which all need the intelligent call center with low cost and high reliability, and the intelligent call center should support multiple media access modes, and provide services for mobile users.

\section{Introduction of SOA and the overall design idea}

With the wide application of Web technology, the operation demands of the call center are more and more in the informationization of enterprise, and it should not only provide the single service for standalone computer, but the opening services for the public, i.e. the completely distributed service, which can sufficiently exert the synergistic effect of the industry chain.

Gartner first proposed the concept of SOA in 1996. At present, it has been another hot word which could replace many software solutions such as the object-oriented architecture, BS architecture, and 3-tier architecture. Therefore, to use SOA to realize the enterprise informationization and establish the operation platform of call center will certainly avoid the information island, and help enterprise to adapt the change of the market more quickly and flexibly.

The principal advantage of SOA is to balance the long-term target and the short-term demand of the government service. When the government function is more and more perfect and the amount is more and more, the structure of SOA must be adopted gradually to perfect the government function through a series of organization principle, capitals, design rules, and implementation rules.

The concrete architecture can begin from the bottom by the method of "from bottom to top", and the codes should be compiled first, and then the support operation logic should be considered in the upper layer, and the SOA will be perfected step by step. In addition, the method of "from top to bottom" can also be adopted.

To avoid the project risk and enhance the flexibility furthest, and realize the SOA in large-scale, most SOA modes are realized by the distributed approach based on standards. According to the development of the system, user can confirm the using scale, and extend the application to the whole system from the local part, and continually use SOA continually. The government should also adopt SOA in proper order to establish the complete SOA framework system. The network SOA can be used to realize the complex processing of backend, and accomplish the integration of technology and concept, and flexibly integrate software when the front end of application program hides the backend, independent of the bottom technology.

\section{E-government and SOA}

SOA belongs to IT strategy, and it organizes the dispersed functions in the E-government application system to the inter-operated service based on standards, and these services can be combined and reused quickly according to the operation demands. SOA is a kind of IT architecture, which can integrate operations as the link services or repeated operation tasks, and interview these services and tasks through the network when needed. These services combined themselves as the needed application program, i.e. the integration of service provider and user 
linked each other, which can accomplish special operation task, and adopt continually changing situation and demand. SOA can not only cover the information from the packaging application, customized application, and legacy system, but the functions and data from the security, content management, and search in IT framework. At present, SOA and $3 \mathrm{G}$ are tow hot words in the call center industry which may develop to these two directions in the future.

\section{Design and implementation of the E-government call center system}

To better provide quick, convenient, and effective services for enterprises and individuals, enhance the work efficiency of various functional departments, and establish the good image of CPC and government in the new period, the government service center should advance with the times and use the advanced SOA technology to develop the government service center call system.

\subsection{Overall design of the system}

The overall design structure chart of the system is seen in Figure 1.

The database server is mainly used for the core database of the system, including the information data of the municipal service center, the feedback information data, and daily management and test database of the call center.

The database server is managed by the information management platform, and it can respond with the voice platform, the artificial terminal, and Web users' request of data inquiry, and execute above client ends' inquiry requests, and send the inquiry results to users.

\subsection{Design of the main function of the system}

\subsubsection{Operation function of the interior network}

The operation of the interior network uses the client/server structure.

\section{(1) Operating function}

It includes signing in/signing out, busy/not busy, incoming call transfer, mute/canceling mute, voice calling, calling out, interior calling, incoming call keeping/canceling keeping, incoming call transfer, manual/automatic answering, manual/automatic releasing, operation hotkey setup, information inquiry of allied enterprises, and inquiry of train time, bus information, and flight information.

(2) Quality inspection center function

The quality inspection center of the call center can effectively supervise and evaluate the operators' work and the running state of the system through many measures such as monitoring, recording, and intercepting.

(3) System administrator function

System administrator function includes five subfunctions. The first subfunction is the enterprise information management which can increase, delete, modify, inquire (multi-condition), and calculate the information of allied enterprises. And it involves the enterprise information table in the database tables. The second subfunction is the call record management which can inquire, make statistics for, modify, and delete the call records. And it involves the call record table in the database tables. The third subfunction is the recording file management which can search the recording files, and delete the needless recording files at any time according to the calling number, the telephone operator number, or the recording time. And it involves the calling record table in the database tables. The fourth subfunction is the telephone operator management which can scan telephone operators' basic information, and perform many operations such as monitoring, recording, playback, and various quality inspections for selected telephone operators. In addition, it can select the window of the telephone operator attribute to scan telephone operator's name, work number, skill sequence, and present working state. The fifth subfunction is the task management, which can inquire and delete all present quality inspection tasks, and classify and rank the task lists respectively according to the telephone operator's work number, type, start time, and quality inspector's work number.

In addition, the system should maintain an authority management table to save the user name, password, the user authority, and when user logs in the system, the system will display different logging picture according to different authorities.

\subsubsection{Service function of the exterior network}

The exterior service network platform adopts the browser/server structure.

The exterior service network platform opens to the outside, and user can interview this network platform through 
the Internet network, and inquire the information.

Its functions mainly conclude the enterprise information inquiry which can inquire the information of allied enterprise such as the brief introduction of enterprise, the introduction of products, and the contact information, the enterprise faith value inquiry which can inquire the faith value of the allied enterprise, the service guidance which can know the procedures and approaches of the service, the policies and regulations which can know the latest laws, regulations, and policies, the affair statics and inquiry which can check how man government affairs have been accomplished.

The design of above functions is very flexible, with good expandability.

\section{Conclusions}

SOA technology has been favored by more and more people, and especially it has been widely applied in the E-government system. The design idea about the application of SOA technology in the E-government system is introduced, and the design and implementation scheme of the complete call center system in the E-government service is provided in this article, and the practical application of this scheme has proved that the design is reasonable, simple, and flexible, with expandability, and it can be extended further in the practice.

\section{References}

$\mathrm{He}$, Xu, et al. (2011). Implementation of the Efficient Communication between SCA Components with the SCA Binding Extension. Computer Engineering \& Science. No.33(3). P. 172-178.

Liu, Jiping, et al. (2006). Research and Implementation of SOA-Based E-government Spatial Information Service. Journal of Liaoning Technical University. No. S1.

Li, Wujian. (2004). Application and Development of the Multimedia Call Center in E-government. Telecommunications Science. No.4.

Mao, Xinsheng. (2007). Principle, Method, and Practice of SOA. Beijing: Electronic Industry Press. July of 2007. P. 6-13.

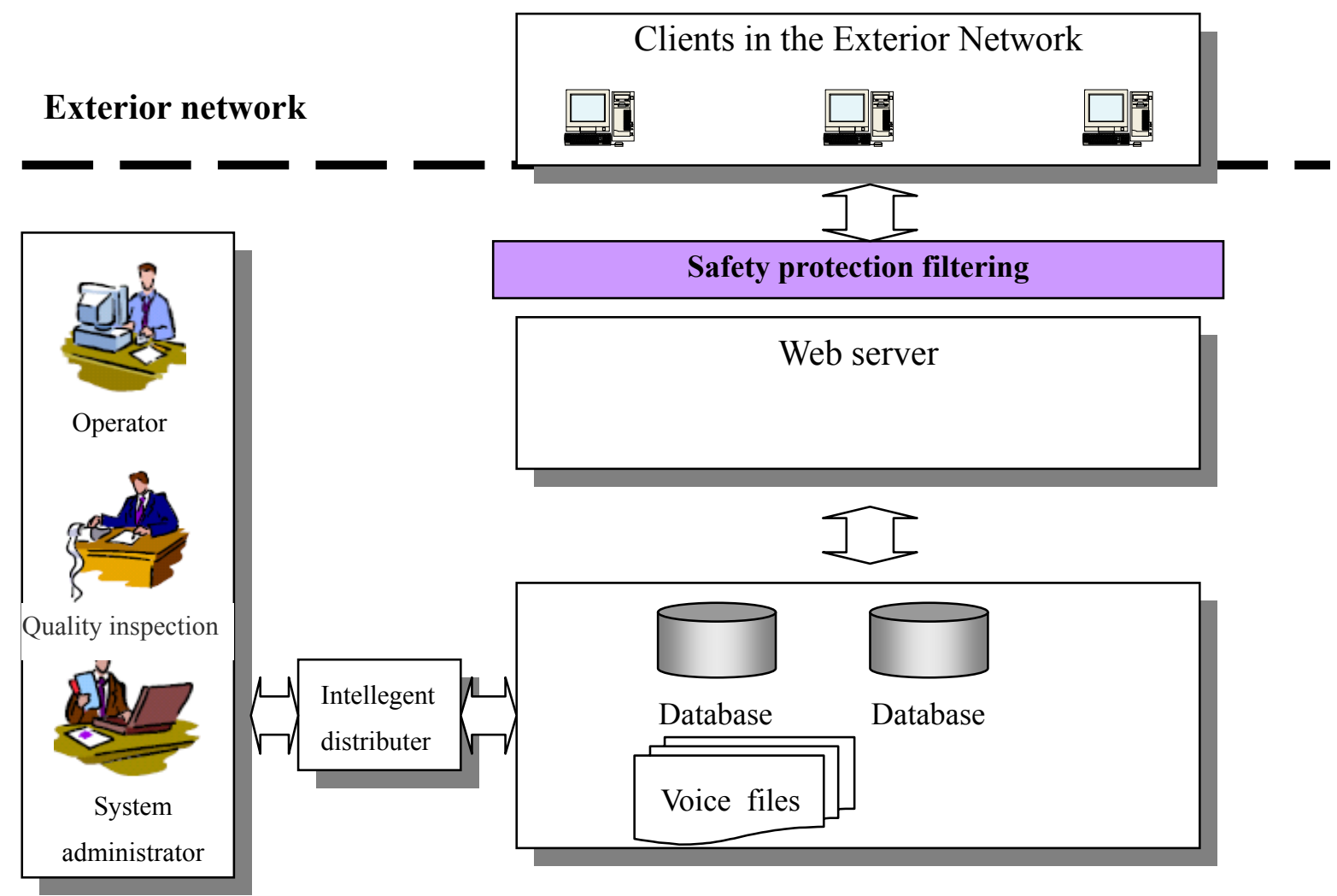

Figure 1. Structure of the Call Center System 